\title{
The Influence of Dietary Lipid Composition on Skeletal Muscle Mitochondria From Mice Following Eight Months of Calorie Restriction
}

\author{
Y. CHEN ${ }^{1}$, K. HAGOPIAN ${ }^{1}$, D. BIBUS ${ }^{2}$, J. M. VILLALBA ${ }^{3}$, G. LÓPEZ-LLUCH ${ }^{4}$, \\ P. NAVAS ${ }^{4}$, K. KIM ${ }^{5}$, J. J. RAMSEY ${ }^{1}$
}

${ }^{1} \mathrm{VM}$ Molecular Biosciences, University of California, Davis, CA, USA, ${ }^{2}$ Lipid Technologies LLC, Austin, MN, USA, ${ }^{3}$ Department of Cell Biology, Physiology and Immunology, University of Cordoba, Cordoba, Spain, ${ }^{4}$ CABD Andalusian Center for Developmental Biology, Pablo de Olavide University - CSIC, CIBERER, Institute of Health Carlos III, Seville, Spain, ${ }^{5}$ Department of Public Health Sciences, University of California, Davis, CA, USA

Received February 15, 2013

Accepted September 16, 2013

On-line November 1, 2013

\section{Summary}

Calorie restriction (CR) has been shown to decrease reactive oxygen species (ROS) production and retard aging in a variety of species. It has been proposed that alterations in membrane saturation are central to these actions of CR. As a step towards testing this theory, mice were assigned to 4 dietary groups (control and 3 CR groups) and fed AIN-93G diets at $95 \%$ (control) or $60 \%$ (CR) of ad libitum for 8 months. To manipulate membrane composition, the primary dietary fats for the CR groups were soybean oil (also used in the control diet), fish oil or lard. Skeletal muscle mitochondrial lipid composition, proton leak, and $\mathrm{H}_{2} \mathrm{O}_{2}$ production were measured. Phospholipid fatty acid composition in $\mathrm{CR}$ mice was altered in a manner that reflected the $n-3$ and $n-6$ fatty acid profiles of their respective dietary lipid sources. Dietary lipid composition did not alter proton leak kinetics between the CR groups. However, the capacity of mitochondrial complex III to produce ROS was decreased in the CR lard compared to the other CR groups. The results of this study indicate that dietary lipid composition can influence ROS production in muscle mitochondria of CR mice. It remains to be determined if lard or other dietary oils can maximize the CRinduced decreases in ROS production.

\section{Key words}

Dietary lipids • Energy restriction • Mitochondria • Phospholipids

- Reactive oxygen species

\section{Corresponding author}

Jon J. Ramsey, VM Molecular Biosciences, University of California, Davis, CA, 95616, USA. Fax: 1-530-752-4698, E-mail: jjramsey@ucdavis.edu

\section{Introduction}

Calorie restriction (CR) without malnutrition has been shown to delay the onset of age-related diseases and increase mean and maximum life spans in a variety of species (Weindruch and Sohal 1997). However, its underlying mechanisms are not fully known. It has been proposed that alterations in mitochondrial membrane lipid composition may be a key contributory factor in the age-delaying effects conferred by CR (Yu 2005). This idea is consistent with the membrane theory of aging which proposes that the number of double bonds in membrane phospholipids is inversely correlated with life span (Hulbert et al. 2007, Pamplona et al. 2002, Pamplona et al. 1998, Portero-Otin et al. 2001) and CR has been reported to alter membrane composition in a manner that decreases long chain n-3 polyunsaturated fatty acid (PUFA) content and decreases the degree of unsaturation of membranes (Faulks et al. 2006, Laganiere and $\mathrm{Yu}$ 1993). This decrease in membrane unsaturation is hypothesized to favor longevity by increasing the resistance of membranes to lipid peroxidation (Pamplona 
et al. 2002, Yu et al. 2002). However, alterations in membrane lipid composition can also influence the function of membrane proteins (Lee 2004). The biochemical functions of mitochondria strongly depend on phospholipids (Daum 1985) whose fatty acid side chains are important contributory factors to membrane structure. Thus, alterations in membrane lipid composition can change membrane structure and influence the functions of proteins that are embedded in the specific lipid medium (Lee 2004).

The inner mitochondrial membrane is one of the primary cellular sites for reactive oxygen species (ROS) production as well as the primary target for oxidative damage. Specifically, the mitochondrial electron transport chain complexes I and III, which reside in the inner mitochondrial membrane, have been identified as major sites of ROS production (Andreyev et al. 2005, Lambert and Brand 2009, Murphy 2009). It is conceivable that alterations in membrane lipid composition could influence aging by modulating ROS production from these complexes. A variety of experimental evidence has confirmed that $\mathrm{CR}$ decreases mitochondrial ROS production in skeletal muscle (Bevilacqua et al. 2004, 2005), liver (Gredilla et al. 2001, Hagopian et al. 2005, Lambert and Merry 2004), heart (Judge et al. 2004, Sohal et al. 1994), kidneys (Sohal et al. 1994) and brain (Sanz et al. 2005, Sohal et al. 1994). Dietary intervention studies also suggest that alterations in membrane lipid composition may influence mitochondrial ROS production (Hagopian et al. 2010, Ramsey et al. 2005). However, it is not clear if changes in membrane lipid composition contribute to CR-induced alterations in ROS production.

CR-related changes in membrane lipid composition could also impact membrane permeability. It has been reported that mitochondrial proton leak shows a positive correlation with membrane unsaturation index and n-3 PUFAs (Brookes et al. 1998, Porter et al. 1996). Also, it has been demonstrated that CR alters mitochondrial proton leak in skeletal muscle (Asami et al. 2008, Johnson et al. 2006). However, it is not entirely known whether CR-induced alterations in membrane composition influence changes in mitochondrial proton leak.

We previously investigated the influence of dietary lipid composition on mitochondrial fatty acid composition, ROS production and mitochondrial proton leak with short-term (1 month) CR in mice (Chen et al. $2012 b)$. The objective of the current study was to determine if dietary lipid source (fish oil, soybean oil or lard) altered skeletal muscle mitochondrial membrane composition, ROS production, and proton leak with chronic CR (eight months) in mice. Skeletal muscle, a post-mitotic tissue, is a major contributor to whole animal oxygen consumption/energy expenditure (Ramsey et al. 2000) and there is considerable evidence that muscle shows increases in oxidative damage with aging (Aoi and Sakuma 2011, Cortopassi and Wong 1999, Marzetti et al. 2009, Sastre et al. 2003). Mitochondrial membrane fatty acid composition may play an important role in determining the magnitude of age-related changes in ROS production and oxidative damage in skeletal muscle. In particular, PUFA-enriched membranes are more susceptible to oxidative damage than those containing primarily saturated and monounsaturated fatty acids (MUFAs) (Hulbert 2005). CR has been shown to mitigate the accumulation of oxidative damage in skeletal muscle with aging (Lass et al. 1998), and it is possible that this may be at least partly due to the CR-induced changes in mitochondrial fatty acid composition (Hulbert 2005, Yu et al. 2002). This study will help indicate if a specific change in membrane fatty acid composition is required for mitochondrial changes commonly reported with $\mathrm{CR}$ and it will determine the influence of dietary lipid composition on skeletal muscle mitochondrial membrane fatty acid composition, ROS production and proton leak in CR mice.

\section{Methods}

\section{Chemicals}

All chemicals and reagents were purchased from Sigma Aldrich (St. Louis, MO), except for protein assay kit (BioRad, Hercules, CA) and bovine serum albumin (MP Biochemicals, Santa Ana, CA).

\section{Animals and diets}

Male C57BL/6 mice were purchased from the Jackson Laboratory (West Sacramento, CA) at 14 weeks of age. After habituation to a commercial rodent chow diet (Harlan Teklad \#7012, Madison, WI) for 14 days, the mice were randomly assigned to 4 dietary groups and fed a modified AIN-93G purified diet (Chen et al. 2012b). The control group was fed $95 \%$ of a pre-determined ad libitum intake $(13.6 \mathrm{kcal} / \mathrm{d})$. This slight restriction in food intake was initiated to prevent excessive weight gain during the study. The three CR dietary groups were maintained on $60 \%$ of the daily allowance of the 
ad libitum intake $(8.6 \mathrm{kcal} / \mathrm{d})$, and these diets were identical except for dietary lipid sources. The modified AIN-93G diets ( $\%$ total $\mathrm{kcal} / \mathrm{d}$ ) contained $20.3 \%$ protein, $63.8 \%$ carbohydrate, and $15.9 \%$ fat. The dietary fat for the control group was soybean oil. The dietary fats for the three CR group were soybean oil (high in n-6 PUFAs, Super Store Industries, Lathrop, CA), fish oil (high in n-3 PUFAs: $\quad 18 \%$ eicosapentaenoic acid, $12 \%$ docosahexaenoic acid, Jedwards International, Inc. Quincy, MA), or lard (high in saturated and monounsaturated fatty acids, ConAgra Foods, Omaha, NE). To prevent linoleic acid deficiency, the diet for the CR-fish group contained some soybean oil ( 55\% linoleic acid) to insure that the requirement for linoleic acid was met. The mice were fed the control or CR diets (modified AIN-93G diets) until they reached 6 months of age after which all mice were switched to a modified AIN-93M diet (Reeves et al. 1993) containing the same primary dietary lipids they were consuming previously (Table 1). The switch from the AIN-93G to AIN-93M diets reflected the protocol used for a parallel life span study. For this study, we wished to maintain the adult mice on a diet that did not contain high amounts of protein. Thus, the AIN-93M diet was selected for longterm maintenance of the mice since the level of protein in this diet was closer to the protein requirement than the AIN-93G diet. The daily energy intake $(\mathrm{kcal} / \mathrm{d})$ remained the same when switching to the AIN-93M diet. To insure linoleic acid requirement, both the CR-fish and the CRlard groups were supplemented with soybean oil (Table 1). The modified AIN-93M diets (\% total kcal/d) contained $14.8 \%$ protein, $75.7 \%$ carbohydrate, and $9.5 \%$ fat. The fatty acid composition of the dietary lipids has been previously reported (Chen et al. 2012b). All mice were housed individually in a vivarium maintained at $22-24{ }^{\circ} \mathrm{C}$ and $40-60 \%$ relative humidity with a $12-\mathrm{h}$ light-dark cycle and free access to water. All experimental procedures were approved by the University of California Institutional Animal Care and Use Committee.

Table 1. AIN-93M diet composition'.

\begin{tabular}{llll}
\hline $\begin{array}{l}\text { Ingredients } \\
\text { (g/100 g diet) }\end{array}$ & \multicolumn{1}{c}{ Dietary group } & CR-Lard \\
\cline { 2 - 4 } Corn starch & Control/CR-Soy & CR-Fish & 46.5 \\
Casein & 46.5 & 46.5 & 14 \\
Maltodextrin & 14 & 14 & 15.1 \\
Sucrose & 15.1 & 15.1 & 10 \\
Soybean oil & 10 & 10 & 0.7 \\
Fish oil & 4 & 1.2 & 0 \\
Lard & 0 & 2.8 & 3.3 \\
Cellulose & 0 & 0 & 5 \\
Mineral mix & 5 & 5 & 3.5 \\
Vitamin mix & 3.5 & 3.5 & 1 \\
L-Cystine & 1 & 1 & 0.18 \\
Choline bitartrate & 0.18 & 0.18 & 0.25 \\
t-Butylhydroquinone & 0.25 & 0.25 & 0.0008 \\
\hline
\end{tabular}

${ }^{1}$ All diets contained AIN-93M mineral mix and AIN-93 vitamin mix obtained from Dyets Inc. (Bethlehem, PA).

\section{Isolation of mitochondria from skeletal muscle}

At the end of 8 months of calorie restriction ( 8 mo CR), mice were euthanized by cervical dislocation after an overnight fast. Muscle mitochondria were isolated as previously described (Seifert et al. 2010) with some modifications. Briefly, muscle from the hindlimb was rapidly dissected and placed in ice-cold basic medium containing $140 \mathrm{mM} \mathrm{KCl}, 20 \mathrm{mM}$ Hepes, $5 \mathrm{mM}$ $\mathrm{MgCl}_{2}$ and $1 \mathrm{mM}$ EGTA (pH 7 at $25^{\circ} \mathrm{C}$ ). Muscle was washed and trimmed of connective tissue and fat, and minced into small pieces in 5 vol of ice-cold homogenization medium containing basic medium with $1 \%$ BSA, $1 \mathrm{mM}$ ATP, and two units of Subtilisin A (protease) per gram muscle wet weight. Muscle was 
incubated in the homogenization media for $2 \mathrm{~min}$ with constant swirling. The muscle solution was then diluted six fold (v/v) using homogenization media without Subtilisin A. The mixture was centrifuged at 10,000 g (Beckman Coulter Model J2-21M) for $10 \mathrm{~min}$ to remove the Subtilisin A. The supernatant was discarded and the pellet was homogenized $(10 \% \mathrm{w} / \mathrm{v}$ in homogenization medium) in an ice cold glass-Teflon motor-driven homogenizer. The homogenate was centrifuged at $500 \mathrm{~g}$ for $10 \mathrm{~min}$ after which the pellet was discarded and the supernatant was centrifuged at $10,000 \mathrm{~g}$ for $10 \mathrm{~min}$. The resulting pellet was re-suspended in wash medium (basic medium with $1 \%$ BSA) and incubated on ice for $5 \mathrm{~min}$ (myofibrillar repolymerization). Samples were then centrifuged at $500 \mathrm{~g}$ for $10 \mathrm{~min}$ in the above wash medium. The retained supernatant was centrifuged at $10,000 \mathrm{~g}$ for $10 \mathrm{~min}$ and the pellet was retained. This pellet was re-suspended in basic medium and centrifuged at $10,000 \mathrm{~g}$ for $10 \mathrm{~min}$. The final pellet was re-suspended in a minimal volume of the basic medium. A portion of this final pellet was used for hydrogen peroxide, proton leak, and lipid peroxidation assays. The rest was stored under liquid nitrogen for lipid analysis.

Purity of the mitochondria was tested by measuring the activity of marker enzymes for lysosomes (acid phosphatase), microsomes (glucose-6-phosphatase) and peroxisomes (urate oxidase) as previously described (Hagopian et al. 2011). The activities of all enzymes were negligible indicating that the mitochondria were free from contamination with other organelles. This was the case for all four dietary treatments.

\section{Protein assays}

Protein concentrations of mitochondrial samples were determined using the BioRad (Hercules, CA) protein assay method, with BSA as the standard.

\section{Organ weight measurements}

Internal organs (brain, liver, heart, kidneys, spleen, and lungs) and fat pads (subcutaneous, epididymal, perirenal, visceral, and interscapular areas) were removed from the mice immediately after sacrifice. All tissues were cleaned of connective tissue and weighed.

\section{Lipid extraction and fatty acid analysis}

Hindlimb muscle mitochondria were used to confirm that dietary lipid manipulations were influencing fatty acid composition of total phospholipids. The isolated mitochondria were shipped on dry ice to Lipid Technologies LLC (Austin, MN) and analyzed for membrane fatty acid composition. Lipids were extracted from the mitochondrial membranes using the Bligh-Dyer extraction (Bligh and Dyer 1959). A mixture of mitochondrial membranes, chloroform/methanol $(2: 1 \mathrm{v} / \mathrm{v})$ and water were prepared in order to recover the lipid in a chloroform layer. Lipid classes were separated by preparative thin layer chromatography and the desired corresponding lipid fractions were scraped from the thin layer plates and methylated with boron trifluoride (10\%) in excess methanol in an $80^{\circ} \mathrm{C}$ water bath for $90 \mathrm{~min}$. The resulting fatty acid methyl esters were extracted with petroleum ether and water and stored frozen for separation and quantification by capillary gas chromatographic analysis (Forsythe et al. 2010). Results were expressed as the percentage of each individual fatty acid in relation to the total fatty acids.

\section{$\mathrm{H}_{2} \mathrm{O}_{2}$ production by skeletal muscle mitochondria}

The rate of mitochondrial $\mathrm{H}_{2} \mathrm{O}_{2}$ production was determined fluorimetrically (excitation $320 \mathrm{~nm}$, emission $400 \mathrm{~nm}$ ) as previously described (Hyslop and Sklar 1984), with modifications, at $37^{\circ} \mathrm{C}$ in a final volume of $3 \mathrm{ml}$ containing (final concentrations) $10 \mathrm{mM}$ potassium phosphate buffer, $\mathrm{pH} 7.4,154 \mathrm{mM} \mathrm{KCl}, 0.1 \mathrm{mM}$ EGTA, $3 \mathrm{mM} \mathrm{MgCl}$, p-hydroxyphenylacetate (PHPA; $500 \mu \mathrm{g}$ ), horseradish peroxidase (4 units), superoxide dismutase (100 U/ml), and mitochondria $(0.1 \mathrm{mg})$. Fluorescence was measured using a Perkin-Elmer LS 55 luminescence spectrometer equipped with a Peltier water heating system and a magnetic stirring sample compartment. Measurements were completed with substrates alone $(10 \mathrm{mM}$ succinate or $10 \mathrm{mM}$ pyruvate/5 $\mathrm{mM}$ malate), substrate plus rotenone $(5 \mu \mathrm{M})$, or substrate plus antimycin A $(5 \mu \mathrm{M})$. Rotenone (complex I inhibitor) and antimycin A (complex III inhibitor) maintain complexes I and/or III in reduced state. The rates of $\mathrm{H}_{2} \mathrm{O}_{2}$ production were expressed as pmol $\mathrm{H}_{2} \mathrm{O}_{2}$ $\mathrm{min}^{-1} \mathrm{mg}^{-1}$ protein. A standard curve generated over a range of $\mathrm{H}_{2} \mathrm{O}_{2}$ concentrations was used to determine the amount of $\mathrm{H}_{2} \mathrm{O}_{2}$ produced.

\section{Measurement of mitochondrial oxygen consumption}

Mitochondrial oxygen consumption (nmol $\mathrm{O} / \mathrm{min} / \mathrm{mg}$ protein) was measured using a previously described method (Venditti et al. 2006) with modifications. Mitochondrial respiration was monitored using a Clarktype oxygen electrode (Hansatech, Norfolk, UK). All measurements were completed at $30^{\circ} \mathrm{C}$ using mitochondria 
Table 2. Organ and body weights (grams) at the end of 8 mo CR in mice consuming a control diet (Control) or CR diets containing either soybean oil (CR-Soy), fish oil (CR-Fish) or lard (CR-Lard) ${ }^{1}$.

\begin{tabular}{lllll}
\hline Body \& Organs & $\begin{array}{l}\text { Control } \\
(\mathbf{n = 1 2})\end{array}$ & $\begin{array}{l}\text { CR-Fish } \\
(\mathbf{n = 1 1 )}\end{array}$ & $\begin{array}{l}\text { CR-Lard } \\
(\mathbf{n = 9})\end{array}$ & $\begin{array}{l}\text { CR-Soy } \\
(\mathbf{n}=\mathbf{1 6})\end{array}$ \\
\hline $\begin{array}{l}\text { Body weight } \\
\text { Liver }\end{array}$ & $35.4 \pm 0.7^{\mathrm{a}}$ & $22.6 \pm 0.3^{\mathrm{b}}$ & $23.2 \pm 0.3^{\mathrm{b}}$ & $23.3 \pm 0.2^{\mathrm{b}}$ \\
Muscle & $1.49 \pm 0.06^{\mathrm{a}}$ & $0.87 \pm 0.02^{\mathrm{b}}$ & $0.93 \pm 0.04^{\mathrm{b}}$ & $0.92 \pm 0.02^{\mathrm{b}}$ \\
Kidneys & $1.39 \pm 0.05^{\mathrm{a}}$ & $1.05 \pm 0.04^{\mathrm{b}}$ & $1.27 \pm 0.03^{\mathrm{a}, \mathrm{c}}$ & $1.14 \pm 0.03^{\mathrm{c}}$ \\
Heart & $0.41 \pm 0.009^{\mathrm{a}}$ & $0.26 \pm 0.005^{\mathrm{b}}$ & $0.25 \pm 0.004^{\mathrm{b}}$ & $0.26 \pm 0.003^{\mathrm{b}}$ \\
Lungs & $0.14 \pm 0.004^{\mathrm{a}}$ & $0.10 \pm 0.003^{\mathrm{b}}$ & $0.11 \pm 0.004^{\mathrm{b}}$ & $0.11 \pm 0.002^{\mathrm{b}}$ \\
Spleen & $0.18 \pm 0.006^{\mathrm{a}}$ & $0.16 \pm 0.002^{\mathrm{b}}$ & $0.17 \pm 0.002^{\mathrm{a}, \mathrm{b}}$ & $0.15 \pm 0.003^{\mathrm{b}}$ \\
Brain & $0.081 \pm 0.002^{\mathrm{a}}$ & $0.052 \pm 0.003^{\mathrm{b}}$ & $0.046 \pm 0.004^{\mathrm{b}}$ & $0.051 \pm 0.002^{\mathrm{b}}$ \\
\hline
\end{tabular}

${ }^{1}$ Values in a row that do not share a common letter indicate a significant difference $(P<0.05)$ between treatments.

Table 3. Fat pad weights (grams) at the end of $8 \mathrm{mo} C R$ in mice consuming a control diet (Control) or CR diets containing either soybean oil (CR-Soy), fish oil (CR-Fish) or lard (CR-Lard). Comparisons are between the treatments within a specific fat pad (row) ${ }^{1}$.

\begin{tabular}{lllll}
\hline Fat pads & $\begin{array}{l}\text { Control } \\
(\mathbf{n = 1 2})\end{array}$ & $\begin{array}{l}\text { CR-Fish } \\
(\mathbf{n = 1 1 )}\end{array}$ & $\begin{array}{l}\text { CR-Lard } \\
(\mathbf{n = 9})\end{array}$ & $\begin{array}{l}\text { CR-Soy } \\
(\mathbf{n = 1 6 )}\end{array}$ \\
\hline $\begin{array}{l}\text { Subcutaneous } \\
\text { Visceral }\end{array}$ & $2.64 \pm 0.14^{\mathrm{a}}$ & $0.70 \pm 0.05^{\mathrm{b}}$ & $0.63 \pm 0.04^{\mathrm{b}}$ & $0.66 \pm 0.05^{\mathrm{b}}$ \\
Epididymal & $0.90 \pm 0.06^{\mathrm{a}}$ & $0.28 \pm 0.02^{\mathrm{b}}$ & $0.38 \pm 0.02^{\mathrm{b}}$ & $0.28 \pm 0.02^{\mathrm{b}}$ \\
Perirenal & $1.87 \pm 0.08^{\mathrm{a}}$ & $0.57 \pm 0.03^{\mathrm{b}}$ & $0.58 \pm 0.02^{\mathrm{b}}$ & $0.53 \pm 0.03^{\mathrm{b}}$ \\
Interscapular & $0.63 \pm 0.047^{\mathrm{a}}$ & $0.08 \pm 0.006^{\mathrm{b}}$ & $0.10 \pm 0^{\mathrm{b}}$ & $0.09 \pm 0.008^{\mathrm{b}}$ \\
\hline
\end{tabular}

${ }^{1}$ Values in rows that do not share a common letter indicate a significant difference $(P<0.05)$ between treatments.

(0.25 $\mathrm{mg}$ mitochondrial protein $/ \mathrm{ml})$ in air-saturated incubation medium $\left(145 \mathrm{mM} \mathrm{KCl}, 5 \mathrm{mM} \mathrm{KH} \mathrm{PO}_{4}, 30 \mathrm{mM}\right.$ Hepes, $3 \mathrm{mM} \mathrm{MgCl}_{2}$, and $0.1 \mathrm{mM}$ EGTA, pH 7.4). Respiration was initiated by the addition of $5 \mathrm{mM}$ succinate (plus $5 \mu \mathrm{M}$ rotenone) in the absence (state 4 ) and in the presence (state 3) of $500 \mu \mathrm{M}$ ADP. Respiratory control ratios (RCR) were calculated as state 3 divided by state 4 respiration rates. The RCR values for the four experimental groups were: Control, 7.0 \pm 0.3 ; CR-soy, 6.7 \pm 0.4 ; CR-fish, 6.4 \pm 0.5 ; and CR-lard, 6.3 \pm 0.3 . These values were not statistically different from each other.

\section{Measurement of proton leak kinetics}

Mitochondrial membrane potential $(\Delta \Psi \mathrm{m})$ in non-phosphorylating skeletal muscle was assessed simultaneously with oxygen consumption measurements using a methyl-triphenyl-phosphonium (TPMP ${ }^{+}$sensitive electrode. All measurements were completed using mitochondria $(0.25 \mathrm{mg} / \mathrm{ml})$ in the abovementioned incubation medium. A TPMP $(0-2.5 \mu \mathrm{M})$ standard curve was generated in each sample prior to the initiation of respiration and membrane potential measurements. Proton leak kinetics were determined by titrating the electron transport chain with incremental additions of malonate (0.1-2.4 mM), an inhibitor of complex II, in the presence of $5 \mathrm{mM}$ succinate, $5 \mu \mathrm{M}$ rotenone, oligomycin $(8 \mu \mathrm{g} / \mathrm{ml})$ and nigericin $(0.08 \mu \mathrm{g} / \mathrm{ml})$ (Ramsey et al. 2004). Membrane potentials were calculated using a modified Nernst equation (Ramsey et al. 2004). A $\mathrm{TPMP}^{+}$binding correction for skeletal muscle of $0.35 \mu \mathrm{l} / \mathrm{mg}$ protein was used for membrane potential calculations (Cadenas et al. 2002).

\section{Measurement of lipid peroxidation levels}

Lipid peroxidation was measured by the thiobarbituric acid reactive substances (TBARS) test (Buege and Aust 1978), except $0.07 \mathrm{mM}$ per assay of butylated hydroxytoluene (BHT) was added to prevent artificial lipid peroxidation during the boiling step (Guerrero et al. 1999). To $1 \mathrm{ml}$ of muscle mitochondrial 
sample (0.25-0.50 mg protein), BHT was added, followed by the addition of $2 \mathrm{ml}$ of TCA-TBA- $\mathrm{HCl}$ reagent $(15 \%$ $\mathrm{w} / \mathrm{v}$ trichloroacetic acid; $0.375 \% \mathrm{w} / \mathrm{v}$ thiobarbituric acid; $0.25 \mathrm{~N}$ hydrochloric acid) and mixed thoroughly. The solution was heated for $15 \mathrm{~min}$ in a boiling water bath, then cooled and centrifuged at $1,000 \mathrm{~g}$ for $10 \mathrm{~min}$ to remove the precipitate. The absorbance of the supernatant was determined at $535 \mathrm{~nm}\left(\varepsilon=1.56 \times 10^{5} \mathrm{M}^{-1} \mathrm{~cm}^{-1}\right)$ against a blank that contained all the reagents minus the mitochondria. Results were expressed as nmol TBARS per mg protein.

\section{Statistical analysis}

All results were expressed as the mean \pm S.E. Normality of the data distribution was determined using the Shapiro-Wilk test. Comparisons between the control and CR-soy group were used to determine the influence of CR on each variable of interest while comparisons among the three CR groups were used to determine the influence of dietary lipids on the variables of interest. Wilcoxon/Kruskal-Wallis tests or ANOVA were performed as appropriate using JMP software (SAS Institute Inc. Cary, NC). A post-hoc Tukey-Kramer test was performed to correct for multiple comparisons.

\section{Results}

\section{Organ and body weights}

Organ and body weights for each of the 4 diet groups are summarized in Table 2. Eight months of CR (Control vs. CR-soy) produced a decrease $(P<0.05)$ in body weight $(34.2 \%)$, liver $(38.3 \%)$, kidney $(36.6 \%)$, heart $(21.4 \%)$, lung $(16.7 \%)$, spleen $(37 \%)$, brain $(9.3 \%)$, and hindlimb muscle $(18 \%)$ weights. CR strikingly decreased the weights of all fat pads $(P<0.05)$, including subcutaneous (75\%), epididymal (71.7\%), perirenal $(85.7 \%)$, visceral $(68.9 \%)$, and interscapular (66.7\%), as shown in Table 3 .

Within the CR groups, the CR-lard mice had higher $(P<0.05)$ muscle weights than the CR-fish group. There were no other differences in organ or fat pad weights between the CR groups.

\section{Mitochondrial total phospholipid fatty acid composition \\ Hindlimb muscle mitochondrial total phospholipid fatty acid composition is presented in Table 4. Lipid analysis showed that muscle mitochondrial membrane lipids changed in a manner which reflected the dietary polyunsaturated fatty acids.}

When investigating the effect of CR (CR-soy vs. control) on mitochondrial phospholipid fatty acid composition, CR was observed to increase $(P<0.05)$ total n-6 fatty acid content. This was primarily due to a $32.1 \%$ increase in 18:2n-6 content in the CR-soy versus control mitochondria. $\mathrm{CR}$ also resulted in a decrease in monounsaturated fatty acid (MUFA) content due to decreases in the content of 16:1n-7 and 18:1n-7. However, CR did not alter unsaturation index (UI), saturated fatty acids (SFA), PUFA, total n-3, and total HUFAs (highly unsaturated fatty acids, three or more double bonds).

To examine the effects of dietary lipids on the mitochondrial membrane fatty acid composition of $\mathrm{CR}$ mice, comparisons were made between the three CR dietary groups. The fish oil group had the highest levels of total n-3 fatty acids, total HUFA, and n-3 HUFA content and concomitantly they had the lowest n- 6 fatty acids and n-6 HUFA content compared to the soy and lard groups. This was due to fish oil induced increases in 20:5n-3, $22: 5 n-3$ and 22:6n-3 content and concomitant decreases in 18:2n-6, 20:3n-6, 20:4n-6 and 22:5n-6 content. The fish oil group also had increased unsaturation index compared to the other diet groups. The lard group had the lowest total n-3 fatty acids and n-3 HUFA content and concomitantly they had the highest total n- 6 fatty acid and n- 6 HUFA content. This was due to lard induced decreases in 18:3n-3, 20:5n-3, 22:5n-3 and 22:6n-3 content and concomitant increases in 20:3n-6, 20:4n-6, 22:4n-6 and 22:5n-6 content. The soybean oil group had the highest 18:2n-6 and 18:3n-3 content.

\section{Mitochondrial $\mathrm{H}_{2} \mathrm{O}_{2}$ production}

The influence of $\mathrm{CR}$ and dietary lipid composition on mitochondrial $\mathrm{H}_{2} \mathrm{O}_{2}$ production is summarized in Figure 1. To examine the effects of $\mathrm{CR}$ on $\mathrm{H}_{2} \mathrm{O}_{2}$ production, comparisons were made between the control and CR-soy groups. Overall, our data indicated that under all conditions tested, there were no differences between the two groups in $\mathrm{H}_{2} \mathrm{O}_{2}$ production regardless of substrates and/or inhibitors used (Fig. 1A-C).

To examine the effects of dietary lipids on $\mathrm{H}_{2} \mathrm{O}_{2}$ production in $\mathrm{CR}$ mice, comparisons were made between the $3 \mathrm{CR}$ dietary groups. Mitochondria respiring on pyruvate/malate (a Complex I-linked substrate) plus rotenone (Fig. 1A) showed similar $\mathrm{H}_{2} \mathrm{O}_{2}$ production irrespective of the dietary fats consumed. Rotenone blocks electron transport to coenzyme $Q$ and maintains Complex I in a reduced state, producing a condition 
Table 4. Fatty acid composition (\%) of total phospholipids from muscle mitochondria of mice consuming a control diet (Control) or CR diets containing lard (CR-Lard) soybean oil (CR-Soy) or fish oil (CR-Fish) for a period of 8 months ${ }^{1}$.

\begin{tabular}{|c|c|c|c|c|}
\hline Fatty acids & $\begin{array}{l}\text { Control } \\
(n=8)\end{array}$ & $\begin{array}{l}\text { CR-Fish } \\
(\mathrm{n}=8)\end{array}$ & $\begin{array}{l}\text { CR-Lard } \\
(n=8)\end{array}$ & $\begin{array}{l}\text { CR-Soy } \\
(n=7)\end{array}$ \\
\hline 14:0 & $0.73 \pm 0.07^{\mathrm{a}}$ & $0.73 \pm 0.06^{\mathrm{a}}$ & $0.48 \pm 0.03^{\mathrm{b}}$ & $0.50 \pm 0.03^{\mathrm{b}}$ \\
\hline 16:0 & $19.9 \pm 0.7$ & $20.3 \pm 0.8$ & $18.3 \pm 0.4$ & $18.2 \pm 0.4$ \\
\hline 18:0 & $12.5 \pm 0.4^{\mathrm{a}}$ & $13.9 \pm 0.5^{\mathrm{a}, \mathrm{b}}$ & $14.3 \pm 0.3^{b}$ & $14.2 \pm 0.4^{\mathrm{b}}$ \\
\hline 20:0 & $0.08 \pm 0.01$ & $0.06 \pm 0.02$ & $0.07 \pm 0.01$ & $0.11 \pm 0.02$ \\
\hline 24:0 & $0.08 \pm 0.003^{\mathrm{a}}$ & $0.12 \pm 0.012^{\mathrm{b}}$ & $0.12 \pm 0.006^{\mathrm{b}}$ & $0.10 \pm 0.005^{\mathrm{a}, \mathrm{b}}$ \\
\hline $16: 1 n-7$ & $3.4 \pm 0.2^{\mathrm{a}}$ & $3.0 \pm 0.2^{\mathrm{a}, \mathrm{c}}$ & $2.6 \pm 0.1^{\mathrm{b}, \mathrm{c}}$ & $2.0 \pm 0.1^{\mathrm{b}}$ \\
\hline $18: 1 n-7$ & $5.3 \pm 0.3^{\mathrm{a}}$ & $4.3 \pm 0.3^{\mathrm{b}}$ & $4.6 \pm 0.2^{\mathrm{a}, \mathrm{b}}$ & $3.9 \pm 0.1^{b}$ \\
\hline $18: \ln -9$ & $5.8 \pm 0.2$ & $5.6 \pm 0.5$ & $6.7 \pm 0.2$ & $6.0 \pm 0.5$ \\
\hline $18: 2 n-6$ & $13.7 \pm 0.5^{\mathrm{a}}$ & $7.7 \pm 0.4^{\mathrm{b}}$ & $15.4 \pm 0.3^{\mathrm{a}}$ & $18.1 \pm 0.7^{\mathrm{c}}$ \\
\hline $18: 3 n-6$ & $0.21 \pm 0.03$ & $0.30 \pm 0.06$ & $0.17 \pm 0.01$ & $0.22 \pm 0.04$ \\
\hline $20: 3 n-6$ & $1.01 \pm 0.03^{\mathrm{a}}$ & $0.45 \pm 0.03^{\mathrm{b}}$ & $1.18 \pm 0.04^{\mathrm{c}}$ & $0.84 \pm 0.04^{\mathrm{d}}$ \\
\hline $20: 4 n-6$ & $8.0 \pm 0.2^{\mathrm{a}}$ & $2.6 \pm 0.1^{\mathrm{b}}$ & $10.9 \pm 0.4^{\mathrm{c}}$ & $8.5 \pm 0.1^{\mathrm{a}}$ \\
\hline $22: 4 n-6$ & $0.89 \pm 0.07^{\mathrm{a}}$ & $0.08 \pm 0.01^{\mathrm{b}}$ & $1.19 \pm 0.04^{\mathrm{c}}$ & $0.52 \pm 0.15^{\mathrm{a}, \mathrm{b}}$ \\
\hline $22: 5 n-6$ & $1.33 \pm 0.10^{\mathrm{a}}$ & $0.43 \pm 0.04^{\mathrm{b}}$ & $3.24 \pm 0.12^{\mathrm{c}}$ & $1.11 \pm 0.08^{\mathrm{a}}$ \\
\hline $18: 3 n-3$ & $0.30 \pm 0.01^{\mathrm{a}}$ & $0.23 \pm 0.01^{\mathrm{b}}$ & $0.14 \pm 0.01^{\mathrm{c}}$ & $0.33 \pm 0.01^{\mathrm{a}}$ \\
\hline $20: 5 n-3$ & $0.11 \pm 0.01^{\mathrm{a}}$ & $1.33 \pm 0.13^{\mathrm{b}}$ & $0.09 \pm 0.01^{\mathrm{a}}$ & $0.16 \pm 0.02^{\mathrm{a}}$ \\
\hline $22: 5 n-3$ & $2.12 \pm 0.13^{\mathrm{a}}$ & $3.57 \pm 0.24^{b}$ & $0.99 \pm 0.03^{\mathrm{c}}$ & $1.73 \pm 0.12^{\mathrm{a}}$ \\
\hline $22: 6 n-3$ & $20.7 \pm 1.6^{\mathrm{a}}$ & $31.4 \pm 1.5^{\mathrm{b}}$ & $15.5 \pm 0.8^{\mathrm{c}}$ & $19.3 \pm 1.4^{\mathrm{a}, \mathrm{c}}$ \\
\hline Unsaturation index & $225.3 \pm 10.1^{\mathrm{a}}$ & $258.6 \pm 10.0^{\mathrm{b}}$ & $214.0 \pm 5.5^{\mathrm{a}}$ & $220.6 \pm 6.6^{\mathrm{a}}$ \\
\hline$\% S F A$ & $33.5 \pm 1.0$ & $35.5 \pm 1.2$ & $33.6 \pm 0.6$ & $33.5 \pm 0.6$ \\
\hline$\% M U F A$ & $15.3 \pm 0.7^{\mathrm{a}}$ & $13.7 \pm 0.9^{\mathrm{a}, \mathrm{b}}$ & $14.7 \pm 0.6^{\mathrm{a}, \mathrm{b}}$ & $12.5 \pm 0.6^{\mathrm{b}}$ \\
\hline$\% P U F A$ & $48.7 \pm 1.6$ & $48.4 \pm 2.0$ & $49.4 \pm 1.1$ & $51.2 \pm 0.9$ \\
\hline$\%$ Total $n-3$ & $23.3 \pm 1.8^{\mathrm{a}}$ & $36.7 \pm 1.8^{\mathrm{b}}$ & $16.8 \pm 0.8^{\mathrm{c}}$ & $21.6 \pm 1.4^{\mathrm{a}, \mathrm{c}}$ \\
\hline$\%$ Total n-6 & $25.4 \pm 0.3^{\mathrm{a}}$ & $11.7 \pm 0.4^{\mathrm{b}}$ & $32.6 \pm 0.5^{\mathrm{c}}$ & $29.6 \pm 0.9^{\mathrm{d}}$ \\
\hline HUFA & $34.6 \pm 2.0^{\mathrm{a}, \mathrm{b}}$ & $40.6 \pm 1.7^{\mathrm{a}}$ & $33.4 \pm 1.2^{\mathrm{b}}$ & $32.8 \pm 1.3^{\mathrm{b}}$ \\
\hline$\% n-3 H U F A^{l}$ & $66.7 \pm 1.4^{\mathrm{a}}$ & $90.4 \pm 0.8^{\mathrm{b}}$ & $50.1 \pm 0.9^{c}$ & $67.2 \pm 1.1^{\mathrm{a}}$ \\
\hline$\% n-6 H U F A^{1}$ & $33.3 \pm 1.4^{\mathrm{a}}$ & $9.6 \pm 0.8^{b}$ & $49.7 \pm 0.9^{c}$ & $32.8 \pm 1.1^{\mathrm{a}}$ \\
\hline
\end{tabular}

${ }^{1}$ Values are percent of total HUFA (highly unsaturated fatty acids, three or more double bonds) amount. Comparisons are between the treatments within a row. Superscripts that do not share a common letter indicate a significant difference $(P<0.05)$ between treatments.

which maximizes ROS production from Complex I. This observation indicated that the ROS producing capacity from complex I was not altered by dietary fats within the $\mathrm{CR}$ regimens. However, $\mathrm{H}_{2} \mathrm{O}_{2}$ production was decreased in the lard compared to fish oil $(P<0.05)$ or soybean oil $(P<0.05) \mathrm{CR}$ groups when mitochondria were respiring on pyruvate/malate plus antimycin A. Antimycin A blocks electron flow at Complex III and maintains both Complexes I and III in a reduced state, thus producing a condition of maximal ROS production. However, since the rotenone results showed no differences between CR groups in capacity to produce ROS from complex I, the pyruvate/malate plus antimycin A results suggest that the CR-lard group had decreased ROS producing capacity from complex III. There was also a clear trend towards decreased $\mathrm{H}_{2} \mathrm{O}_{2}$ production in the CR-lard compared to other $\mathrm{CR}$ groups $(P=0.07$ : CR-lard vs. $\mathrm{CR}$-soy; $P=0.08$ : CR-lard vs. CR-fish) for pyruvate/malate/succinate (Complex I and II-linked substrates) plus antimycin A (Fig. 1C). There were no differences in $\mathrm{H}_{2} \mathrm{O}_{2}$ production between any of the $\mathrm{CR}$ groups when mitochondria were respiring on succinate (Complex II-linked substrate) (Fig. 1B and 1C). Succinate was used as a substrate to investigate backflow into complex I. The lack of significant differences between $\mathrm{CR}$ groups in mitochondria respiring on succinate suggests that dietary lipids had little influence on ROS produced from backflow into complex I. 

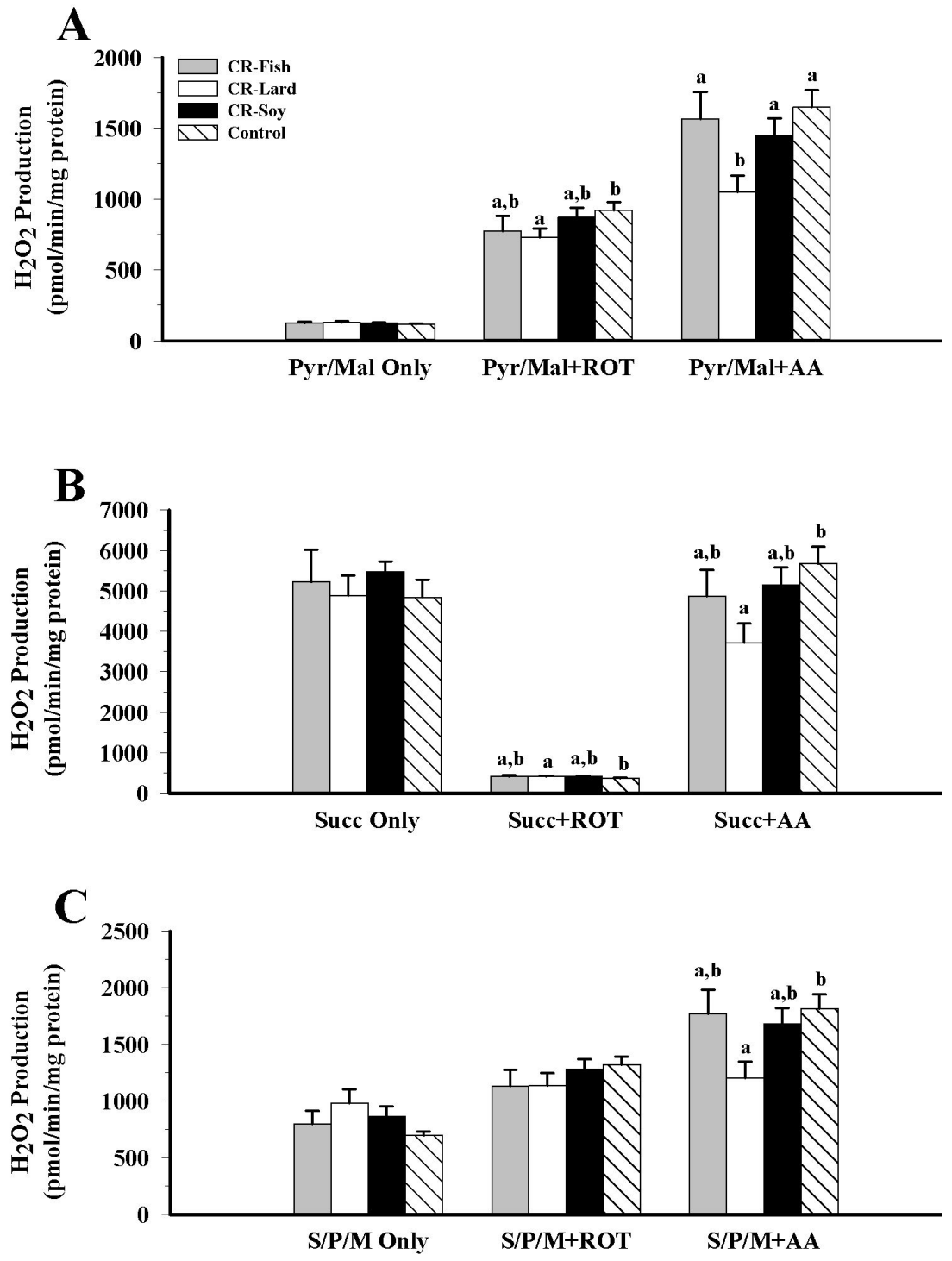

Fig. 1. Hydrogen peroxide production in muscle mitochondria at the end of $8 \mathrm{mo} C R$ from mice consuming a control diet (Control) or CR diets containing lard (CRLard), soybean oil (CR-Soy), or fish oil (CRFish). All measurements were completed on freshly isolated mitochondria. $\mathrm{H}_{2} \mathrm{O}_{2}$ production was monitored in mitochondria respiring on Pyruvate/Malate (Panel A), Succinate (Panel B), or Succinate plus Pyruvate/Malate (Panel C). All comparisons were within substrate only or within the substrate and inhibitor combination. Bars that do not share a common letter indicate a significant difference $(P<0.05)$ between treatments. All values are mean $\pm \mathrm{SEM}$ $(n=7-9) . A A$, Antimycin A; ROT, Rotenone

\section{Mitochondrial proton leak kinetics}

Mitochondrial proton leak kinetics curves are summarized in Figure 2. To examine the effects of CR on proton leak kinetics, comparisons were made between the CR-soy and the control groups. Our data showed that state 4 oxygen consumption and membrane potential (furthest points to the right on the proton leak kinetics plot) were not significantly different between the CR-soy and control groups. When assessing the effects of dietary fats on proton leak, comparisons were made between the $3 \mathrm{CR}$ diet groups. The results indicated that dietary lipid composition did not markedly influence mitochondrial proton leak in skeletal muscle of CR mice.

\section{Lipid peroxidation in skeletal muscle mitochondria}

TBARS were measured to assess lipid peroxidation in skeletal muscle mitochondria from the four groups of mice (Fig. 3). Comparisons between the control and CR-soy groups indicated no change in TBARS levels following eight months of CR. Comparisons between the $\mathrm{CR}$ groups indicated that dietary lipids did not markedly influence the levels of TBARS.

\section{Discussion}

It has been proposed that alterations in mitochondrial membrane fatty acid composition may play a central role in the actions of CR (Yu et al. 2002). To test this idea, membrane fatty acid composition was manipulated in CR mice by feeding the animals diets that differed in lipid composition. The objective of the study was to determine if mitochondrial phospholipid fatty acid composition influenced mitochondrial ROS production and proton leak with CR. To determine the efficacy of using this approach, it was important to determine if 


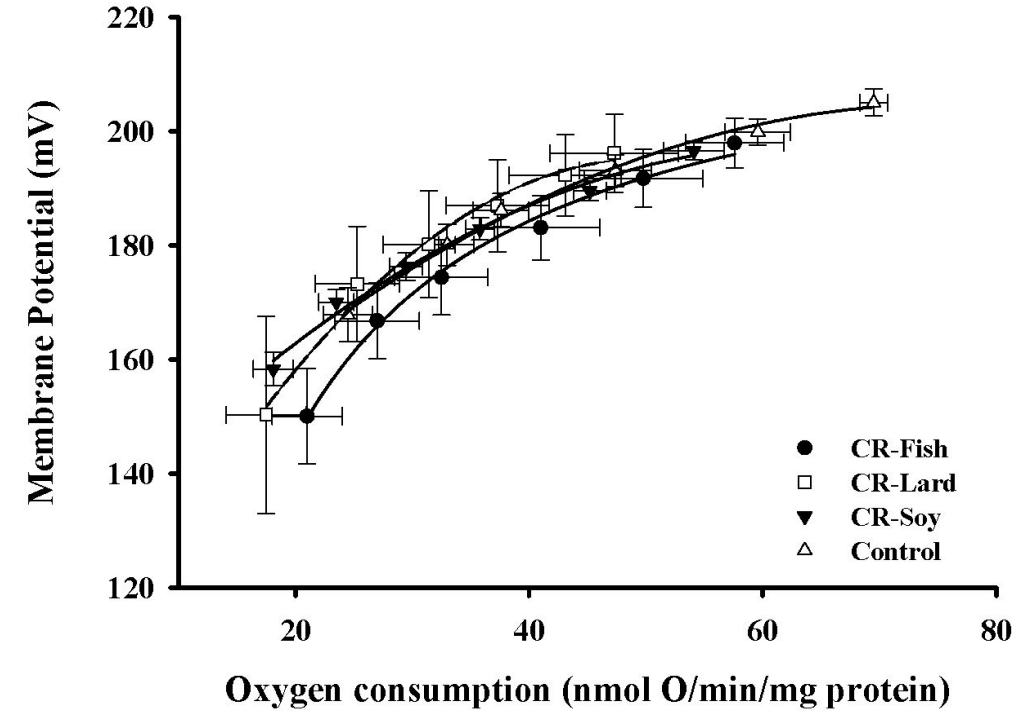

Fig. 2. Proton leak kinetics curves in muscle mitochondria at the end of $8 \mathrm{mo}$ CR from mice consuming a control diet (Control) or CR diets containing lard (CR-Lard), soybean oil (CR-Soy), or fish oil (CR-Fish). Leak-dependent respiration and membrane potential were measured simultaneously using a Clark-type electrode and a TPMP $^{+}$-sensitive electrode, respectively. The furthest point on the right in each panel represents state 4 respiration. All measurements were completed using mitochondria $(0.25 \mathrm{mg} / \mathrm{ml})$ in incubation medium $(145 \mathrm{mM} \mathrm{KCl}$,

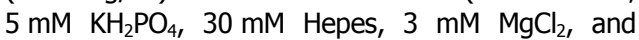
$0.1 \mathrm{mM}$ EGTA, pH 7.4). A TPMP ${ }^{+}(0-2.5 \mu \mathrm{M})$ standard curve was generated in each sample prior to the initiation of respiration and membrane potential measurements. All assays were performed in the presence of $5 \mathrm{mM}$ succinate, $5 \mu \mathrm{M}$ rotenone, oligomycin $(8 \mu \mathrm{g} / \mathrm{ml})$ and nigericin $(0.08 \mu \mathrm{g} / \mathrm{ml})$, and incremental additions of malonate (0.1-2.4 mM). All values are mean \pm SEM $(n=7-9)$.

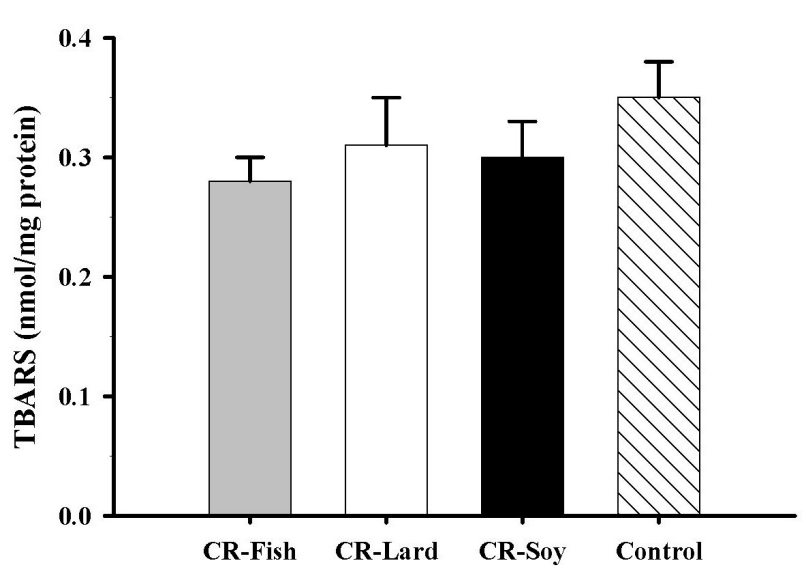

Fig. 3. TBARS levels in hindlimb muscle mitochondria at the end of $8 \mathrm{mo}$ CR from mice consuming a control diet (Control) or CR diets containing lard (CR-Lard), soybean oil (CR-Soy), or fish oil (CR-Fish). No differences were observed between mitochondria from different treatments. All values are expressed as $\mathrm{nmol} / \mathrm{mg}$ protein and presented as mean \pm SEM $(n=7-9)$.

mitochondrial fatty acids are sensitive to dietary lipid composition in mice maintained on CR for 8 months. In ad libitum fed animals, it has been shown that dietary lipids can alter the fatty acid profile of mitochondrial membranes in multiple tissues, including liver (Quiles et al. 2002, Ramsey et al. 2005, Tahin et al. 1981), heart (Quiles et al. 2002, Tahin et al. 1981, Yamaoka et al. 1988), brain (Tahin et al. 1981), and skeletal muscle (Quiles et al. 2002). However, there is little information to indicate if these same changes in mitochondrial fatty acids are observed in $\mathrm{CR}$ animals. We have previously shown that mitochondrial fatty acid composition is altered to reflect dietary polyunsaturated fatty acid composition in mice maintained on $\mathrm{CR}$ for 1 month
(Chen et al. 2012b). The results of the present study indicate that dietary lipid composition also has a substantial influence on mitochondrial phospholipid fatty acids at 8 months of CR. Specifically, in CR mice fish oil markedly increased n-3 fatty acids and soybean oil increased 18:2n-6 levels in mitochondrial phospholipids. Our results demonstrate that muscle mitochondrial fatty acid composition is sensitive to dietary lipid composition in mice maintained on long-term ( 8 months) CR.

It has been reported that $\mathrm{CR}$ increases the content of 18:2n-6 and decrease long chain polyunsaturated fatty acids of membrane phospholipids in liver (Laganiere and $\mathrm{Yu}$ 1989, 1993), spleen (Venkatraman and Fernandes 1992) and heart (Lee et al. 1999). The results of the present study are consistent with the idea that CR increases the level of 18:2n-6 in mitochondrial phospholipids, however, we found no evidence that $\mathrm{CR}$ decreases long chain polyunsaturated fatty acids or unsaturation index in skeletal muscle mitochondria. Thus, it does not appear that a sustained decrease in membrane unsaturation is a mechanism contributing to the actions of $\mathrm{CR}$ in skeletal muscle mitochondria. However, it is possible that additional changes in fatty acid composition may occur with age and/or duration of CR. In support of this idea, it has been reported that both level of $\mathrm{CR}$ and length of $\mathrm{CR}$ influence skeletal muscle phospholipid fatty acid composition (Faulks et al. 2006). Similarly, CR-induced changes in mitochondrial phospholipid fatty acid composition were not entirely uniform between our 1 month (Chen et al. 2012b) and 8 month $C R$ studies. In particular, a significant CR-induced increase in mitochondrial 18:2n-6 level was only observed at 8 months of CR. Thus, 
additional studies at multiple time points are likely needed to completely characterize the influence of CR and lipid composition on mitochondria phospholipid fatty acids.

One way that mitochondrial membrane fatty acids could influence aging is by altering mitochondrial ROS production. CR has been reported to decrease mitochondrial ROS production in a variety of tissues (Gredilla and Barja 2005, Sohal and Weindruch 1996). Studies in rats have reported that skeletal muscle mitochondrial ROS production is decreased with longterm (1 year or longer) CR (Bevilacqua et al. 2005, Drew et al. 2003), and either decreased (Bevilacqua et al. 2004) or not changed (Gredilla et al. 2004) with short-term CR. In mice, it has been shown that muscle ROS production is not altered with short-term (6 months or less) CR (Chen et al. 2012b, Faulks et al. 2006) in mitochondria respiring on substrates in the absence of electron transport chain inhibitors. The results of the present study are consistent with these studies in mice and indicate that $\mathrm{CR}$ and control animals show similar levels of skeletal muscle mitochondrial ROS production at 8 months of CR. Thus, the CR-induced changes in mitochondrial fatty acid composition in the CR-soy group alone were not sufficient to induce alteration in ROS production at 8 months of CR. However, there is evidence that CR prevents age-related increases in skeletal muscle ROS production in mice (Lass et al. 1998) and it is possible that studies of longer duration are needed to consistently see changes in muscle ROS production. The reason(s) for the differences between studies in ROS production in response to $\mathrm{CR}$ is not clear. It does not appear to be due to species differences since similar responses to $\mathrm{CR}$ have been observed in both rats and mice (Walsh et al. 2014). The differences may be influenced by the level of CR, age or diet composition. Studies do indicate that lipid (Chen et al. 2012a, Chen et al. 2012b, Ramsey et al. 2005) and protein (Caro et al. 2009, Gomez et al. 2011) composition of diets can influence ROS production. However, additional studies are needed to determine the extent to which diet composition, age or magnitude of CR may influence CR-related changes in ROS production.

The primary sites of ROS production in mitochondria are complexes I and III of the ETC (Gredilla et al. 2001). Since ROS are produced by these membrane-bound proteins, it is conceivable that the rate of ROS production could be influenced by mitochondrial phospholipid fatty acid composition. Changes in lipids can influence mitochondrial membrane structure and stability and affect the function of individual enzymes (Daum 1985). In particular, fatty acid composition of cardiolipin has been shown to influence the activities of ETC enzymes (Hoch 1992). However, little is known about the influence of membrane lipid composition on mitochondrial ROS production. Previous investigations (Hagopian et al. 2010, Ramsey et al. 2005) have shown that increased n-3 HUFA content in liver mitochondrial membrane phospholipids is associated with decreased ROS production. However, it is unclear whether fatty acid composition of mitochondrial phospholipids influence muscle mitochondrial ROS production in a manner similar to that of liver. The results from our one month CR study indicate that dietary lipid composition did not alter skeletal muscle $\mathrm{H}_{2} \mathrm{O}_{2}$ production in CR mice, despite producing major changes in mitochondrial phospholipid fatty acid composition (Chen et al. 2012b). The results of the present study suggest that length of CR and/or age may induce changes in mitochondrial ROS production between dietary lipid groups. In particular, $\mathrm{H}_{2} \mathrm{O}_{2}$ production was decreased in the CR-lard compared to other CR groups when maximal ROS production was induced by adding the Complex III inhibitor antimycin A to mitochondria respiring on pyruvate/malate or pyruvate/malate/succinate. Since no decrease in $\mathrm{H}_{2} \mathrm{O}_{2}$ production was observed in this group with rotenone (a complex I inhibitor), these results suggest that capacity for ROS production from Complex III is decreased in the CR-lard versus other CR groups. The use of inhibitors allows chemical dissection of the electron transport chain (ETC) and identification of the specific complexes responsible for ROS production. The inhibitors maintain specific components of the ETC in a reduced state and produce conditions which maximize ROS production. They may identify changes in capacity for ROS production that would be missed with the use of substrates alone and may provide an indication of ROS production under physiological conditions which limit ETC activity (such as decreased oxygen or ADP levels). Nonetheless, the results of the current study provide support for the idea that dietary lipid composition does influence ROS production in skeletal muscle mitochondria of CR animals.

It is also possible that mitochondrial fatty acid composition could influence mitochondrial proton leak. Proton leak is a process where protons bypass the ATP synthase and passively cross the mitochondrial inner membrane. It has been shown that basal proton leak increases with age (Hagen et al. 1997, Harper et al. 1998, 
Lal et al. 2001) and it has been proposed that CR may oppose this age-related increase and improve mitochondrial efficiency by inducing a sustained decrease in proton leak (Ramsey et al. 2000). Factors affecting the rates of proton leak include uncoupling proteins (UCP 2 and 3) (Brookes 2005), ANT (Brookes 2005), and possibly phospholipids (Brand 2005). It has been shown in mice that skeletal muscle proton leak is either not altered or decreased with $\mathrm{CR}$ depending on duration of CR and/or animal age (Asami et al. 2008). We previously showed that there was a trend towards a decrease in skeletal muscle proton leak at one month of CR (Chen et al. 2012b), although any difference had disappeared by 8 months of CR. Existing skeletal muscle data supports the idea that $\mathrm{CR}$ does not produce uniform changes in proton leak kinetics across time when compared to control animals. It has previously been shown that these changes in proton leak kinetics are primarily due to agerelated changes in control rather than CR mice (Asami et al. 2008). Thus, it is possible that time-related changes in proton leak kinetics between $\mathrm{CR}$ and control mice reflect the fact that $\mathrm{CR}$ mitigates age-related changes in proton leak.

Unsaturation index and level of n-3 PUFA in mitochondrial inner membrane phospholipids has been shown to be positively correlated with proton leak in comparative studies using liver mitochondria (Brookes et al. 1998, Porter et al. 1996) or liposomes prepared from liver mitochondria (Brand et al. 1994). However, the influence of dietary lipids and mitochondrial membrane lipid composition on proton leak in skeletal muscle is not entirely clear. The results of our studies indicate that dietary lipids and mitochondrial phospholipid composition have little influence on skeletal muscle mitochondrial proton leak in CR animals. This reflects the fact that only a slight decrease in skeletal muscle mitochondrial proton leak was observed in the CR-lard compared to other CR groups at one month of CR (Chen et al. 2012b) and no differences in proton leak were observed between the CR groups at eight months of CR. This lack of change in skeletal muscle mitochondrial proton leak occurred despite the fact that diet produced large changes in mitochondrial phospholipid fatty acid composition. These results indicate that basal proton leak in skeletal muscle mitochondria is primarily a function of membrane proteins and is largely insensitive to membrane fatty acid composition.
Lipid peroxidation is one factor that could influence the comparisons in the present study. Previous research has demonstrated an inverse correlation in mammalian species between peroxidation index and lifespan (Hulbert 2008) and it has been proposed that CR may retard aging by making membranes more resistant to peroxidation ( $\mathrm{Yu}$ et al. 2002). An increased degree of unsaturation in membrane phospholipids, as a result of fish oil consumption, may deplete some antioxidants and augment membrane susceptibility to lipid peroxidation. Experimental manipulation of membrane composition allows us to assess the consequences of varying membrane compositions on oxidative damage. It should be noted that to prevent membrane oxidative damage, the fish oil fed CR group was provided with twice the amount of the dietary antioxidant t-butylhydroquinone than the other groups. Our TBARS measurements demonstrated there were no significant differences between any of the groups of mice in mitochondrial lipid peroxidation. This indicates that none of the mitochondrial comparisons were influenced by differences in level of lipid peroxidation between groups.

The present study indicates that skeletal muscle phospholipid fatty acid composition in mice following 8month CR is altered in a manner that reflects the n-3 and n- 6 fatty acid profiles of their respective dietary lipid sources. Despite these changes in mitochondrial fatty acid composition, dietary lipid composition had no influence on skeletal muscle mitochondrial proton leak at 8 months of CR. Dietary lipid composition did, however, have an influence on mitochondrial ROS production in the CR mice. In particular, capacity for ROS production from Complex III was decreased in the CR-lard compared to other CR groups. The results of this study indicate that dietary lipid composition can influence ROS production in mice maintained on $\mathrm{CR}$ for 8 months. It remains to be determined if lard or other mixtures of dietary oils can maximize decreases in skeletal muscle ROS production with long-term $\mathrm{CR}$ in older animals.

\section{Conflict of Interest}

There is no conflict of interest.

\section{Acknowledgements}

This work was supported by the National Institutes of Health grants R01 AG028125 and P01 AG025532. 


\section{References}

ANDREYEV AY, KUSHNAREVA YE, STARKOV AA: Mitochondrial metabolism of reactive oxygen species. Biochemistry 70: 200-214, 2005.

AOI W, SAKUMA K: Oxidative stress and skeletal muscle dysfunction with aging. Curr Aging Sci 4: 101-109, 2011.

ASAMI DK, MCDONALD RB, HAGOPIAN K, HORWITZ BA, WARMAN D, HSIAO A, WARDEN C, RAMSEY JJ: Effect of aging, caloric restriction, and uncoupling protein 3 (UCP3) on mitochondrial proton leak in mice. Exp Gerontol 43: 1069-1076, 2008.

BEVILACQUA L, RAMSEY JJ, HAGOPIAN K, WEINDRUCH R, HARPER ME: Effects of short- and medium-term calorie restriction on muscle mitochondrial proton leak and reactive oxygen species production. Am J Physiol 286: E852-E861, 2004.

BEVILACQUA L, RAMSEY JJ, HAGOPIAN K, WEINDRUCH R, HARPER ME: Long-term caloric restriction increases UCP3 content but decreases proton leak and reactive oxygen species production in rat skeletal muscle mitochondria. Am J Physiol 289: E429-E438, 2005.

BLIGH EG, DYER WJ: A rapid method of total lipid extraction and purification. Can J Biochem Physiol 37: 911-917, 1959.

BRAND MD: The efficiency and plasticity of mitochondrial energy transduction. Biochem Soc Trans 33: 897-904, 2005.

BRAND MD, COUTURE P, HULBERT AJ: Liposomes from mammalian liver mitochondria are more polyunsaturated and leakier to protons than those from reptiles. Comp Biochem Physiol Biochem Mol Biol 108: 181-188, 1994.

BROOKES PS: Mitochondrial H(+) leak and ROS generation: an odd couple. Free Radic Biol Med 38: 12-23, 2005.

BROOKES PS, BUCKINGHAM JA, TENREIRO AM, HULBERT AJ, BRAND MD: The proton permeability of the inner membrane of liver mitochondria from ectothermic and endothermic vertebrates and from obese rats: correlations with standard metabolic rate and phospholipid fatty acid composition. Comp Biochem Physiol B Biochem Mol Biol 119: 325-334, 1998.

BUEGE JA, AUST SD: Microsomal lipid peroxidation. Methods Enzymol 52: 302-310, 1978.

CADENAS S, ECHTAY KS, HARPER JA, JEKABSONS MB, BUCKINGHAM JA, GRAU E, ABUIN A, CHAPMAN H, CLAPHAM JC, BRAND MD: The basal proton conductance of skeletal muscle mitochondria from transgenic mice overexpressing or lacking uncoupling protein-3. J Biol Chem 277: 2773-2778, 2002.

CARO P, GOMEZ J, SANCHEZ I, NAUDI A, AYALA V, LOPEZ-TORRES M, PAMPLONA R, BARJA G: Forty percent methionine restriction decreases mitochondrial oxygen radical production and leak at complex I during forward electron flow and lowers oxidative damage to proteins and mitochondrial DNA in rat kidney and brain mitochondria. Rejuvenation Res 12: 421-434, 2009.

CHEN Y, HAGOPIAN K, BIBUS D, VILLALBA JM, LOPEZ-LLUCH G, NAVAS P, KIM K, MCDONALD RB, RAMSEY JJ: The influence of dietary lipid composition on liver mitochondria from mice following 1 month of calorie restriction. Biosci Rep 33: 83-95, 2012a.

CHEN Y, HAGOPIAN K, MCDONALD RB, BIBUS D, LOPEZ-LLUCH G, VILLALBA JM, NAVAS P, RAMSEY JJ: The influence of dietary lipid composition on skeletal muscle mitochondria from mice following 1 month of calorie restriction. J Gerontol A Biol Sci Med Sci 67: 1121-1131, 2012b.

CORTOPASSI GA, WONG A: Mitochondria in organismal aging and degeneration. Biochim Biophys Acta 1410: 183193, 1999.

DAUM G: Lipids of mitochondria. Biochim Biophys Acta 822: 1-42, 1985.

DREW B, PHANEUF S, DIRKS A, SELMAN C, GREDILLA R, LEZZA A, BARJA G, LEEUWENBURGH C: Effects of aging and caloric restriction on mitochondrial energy production in gastrocnemius muscle and heart. Am J Physiol 284: R474-R480, 2003.

FAULKS SC, TURNER N, ELSE PL, HULBERT AJ: Calorie restriction in mice: effects on body composition, daily activity, metabolic rate, mitochondrial reactive oxygen species production, and membrane fatty acid composition. J Gerontol A Biol Sci Med Sci 61: 781-794, 2006. 
FORSYTHE CE, PHINNEY SD, FEINMAN RD, VOLK BM, FREIDENREICH D, QUANN E, BALLARD K, PUGLISI MJ, MARESH CM, KRAEMER WJ, BIBUS DM, FERNANDEZ ML, VOLEK JS: Limited effect of dietary saturated fat on plasma saturated fat in the context of a low carbohydrate diet. Lipids 45: 947-962, 2010.

GOMEZ J, SANCHEZ-ROMAN I, GOMEZ A, SANCHEZ C, SUAREZ H, LOPEZ-TORRES M, BARJA G: Methionine and homocysteine modulate the rate of ROS generation of isolated mitochondria in vitro. J Bioenerg Biomembr 43: 377-386, 2011.

GREDILLA R, BARJA G: Minireview: the role of oxidative stress in relation to caloric restriction and longevity. Endocrinology 146: 3713-3717, 2005.

GREDILLA R, BARJA G, LOPEZ-TORRES M: Effect of short-term caloric restriction on $\mathrm{H}_{2} \mathrm{O}_{2}$ production and oxidative DNA damage in rat liver mitochondria and location of the free radical source. J Bioenerg Biomembr 33: 279-287, 2001.

GREDILLA R, PHANEUF S, SELMAN C, KENDAIAH S, LEEUWENBURGH C, BARJA G: Short-term caloric restriction and sites of oxygen radical generation in kidney and skeletal muscle mitochondria. Ann $N$ Y Acad Sci 1019: 333-342, 2004.

GUERRERO A, PAMPLONA R, PORTERO-OTIN M, BARJA G, LOPEZ-TORRES M: Effect of thyroid status on lipid composition and peroxidation in the mouse liver. Free Radic Biol Med 26: 73-80, 1999.

HAGEN TM, YOWE DL, BARTHOLOMEW JC, WEHR CM, DO KL, PARK JY, AMES BN: Mitochondrial decay in hepatocytes from old rats: membrane potential declines, heterogeneity and oxidants increase. Proc Natl Acad Sci US A 94: 3064-3069, 1997.

HAGOPIAN K, HARPER ME, RAM JJ, HUMBLE SJ, WEINDRUCH R, RAMSEY JJ: Long-term calorie restriction reduces proton leak and hydrogen peroxide production in liver mitochondria. Am J Physiol 288: E674-E684, 2005.

HAGOPIAN K, WEBER KL, HWEE DT, VAN EENENNAAM AL, LOPEZ-LLUCH G, VILLALBA JM, BURON I, NAVAS P, GERMAN JB, WATKINS SM, CHEN Y, WEI A, MCDONALD RB, RAMSEY JJ: Complex Iassociated hydrogen peroxide production is decreased and electron transport chain enzyme activities are altered in n-3 enriched fat-1 mice. PLoS One 5: e12696, 2010.

HAGOPIAN K, CHEN Y, SIMMONS DOMER K, SOO HOO R, BENTLEY T, MCDONALD RB, RAMSEY JJ: Caloric restriction influences hydrogen peroxide generation in mitochondrial sub-populations from mouse liver. J Bioenerg Biomembr 43: 227-236, 2011.

HARPER ME, MONEMDJOU S, RAMSEY JJ, WEINDRUCH R: Age-related increase in mitochondrial proton leak and decrease in ATP turnover reactions in mouse hepatocytes. Am J Physiol 275: E197-E206, 1998.

HOCH FL: Cardiolipins and biomembrane function. Biochim Biophys Acta 1113: 71-133, 1992.

HULBERT AJ: On the importance of fatty acid composition of membranes for aging. J Theor Biol 234: 277-288, 2005.

HULBERT AJ: Explaining longevity of different animals: is membrane fatty acid composition the missing link? Age (Dordr) 30: 89-97, 2008.

HULBERT AJ, PAMPLONA R, BUFFENSTEIN R, BUTTEMER WA: Life and death: metabolic rate, membrane composition, and life span of animals. Physiol Rev 87: 1175-1213, 2007.

HYSLOP PA, SKLAR LA: A quantitative fluorimetric assay for the determination of oxidant production by polymorphonuclear leukocytes: its use in the simultaneous fluorimetric assay of cellular activation processes. Anal Biochem 141: 280-286, 1984.

JOHNSON G, ROUSSEL D, DUMAS JF, DOUAY O, MALTHIERY Y, SIMARD G, RITZ P: Influence of intensity of food restriction on skeletal muscle mitochondrial energy metabolism in rats. Am J Physiol 291: E460-E467, 2006.

JUDGE S, JUDGE A, GRUNE T, LEEUWENBURGH C: Short-term CR decreases cardiac mitochondrial oxidant production but increases carbonyl content. Am J Physiol 286: R254-R259, 2004.

LAGANIERE S, YU BP: Effect of chronic food restriction in aging rats. I. Liver subcellular membranes. Mech Ageing Dev 48: 207-219, 1989.

LAGANIERE S, YU BP: Modulation of membrane phospholipid fatty acid composition by age and food restriction. Gerontology 39: 7-18, 1993. 
LAL SB, RAMSEY JJ, MONEMDJOU S, WEINDRUCH R, HARPER ME: Effects of caloric restriction on skeletal muscle mitochondrial proton leak in aging rats. J Gerontol A Biol Sci Med Sci 56: B116-B122, 2001.

LAMBERT AJ, BRAND MD: Reactive oxygen species production by mitochondria. Methods Mol Biol 554: 165-181, 2009.

LAMBERT AJ, MERRY BJ: Effect of caloric restriction on mitochondrial reactive oxygen species production and bioenergetics: reversal by insulin. Am J Physiol 286: R71-R79, 2004.

LASS A, SOHAL BH, WEINDRUCH R, FORSTER MJ, SOHAL RS: Caloric restriction prevents age-associated accrual of oxidative damage to mouse skeletal muscle mitochondria. Free Radic Biol Med 25: 1089-1097, 1998.

LEE AG: How lipids affect the activities of integral membrane proteins. Biochim Biophys Acta 1666: 62-87, 2004.

LEE J, YU BP, HERLIHY JT: Modulation of cardiac mitochondrial membrane fluidity by age and calorie intake. Free Radic Biol Med 26: 260-265, 1999.

MARZETTI E, LEES HA, WOHLGEMUTH SE, LEEUWENBURGH C: Sarcopenia of aging: underlying cellular mechanisms and protection by calorie restriction. Biofactors 35: 28-35, 2009.

MURPHY MP: How mitochondria produce reactive oxygen species. Biochem J 417: 1-13, 2009.

PAMPLONA R, PORTERO-OTIN M, RIBA D, RUIZ C, PRAT J, BELLMUNT MJ, BARJA G: Mitochondrial membrane peroxidizability index is inversely related to maximum life span in mammals. J Lipid Res 39: 19891994, 1998.

PAMPLONA R, BARJA G, PORTERO-OTIN M: Membrane fatty acid unsaturation, protection against oxidative stress, and maximum life span: a homeoviscous-longevity adaptation? Ann N Y Acad Sci 959: 475-490, 2002.

PORTER RK, HULBERT AJ, BRAND MD: Allometry of mitochondrial proton leak: influence of membrane surface area and fatty acid composition. Am J Physiol 271: R1550-R1560, 1996.

PORTERO-OTIN M, BELLMUNT MJ, RUIZ MC, BARJA G, PAMPLONA R: Correlation of fatty acid unsaturation of the major liver mitochondrial phospholipid classes in mammals to their maximum life span potential. Lipids 36: 491-498, 2001.

QUILES JL, MARTINEZ E, IBANEZ S, OCHOA JJ, MARTIN Y, LOPEZ-FRIAS M, HUERTAS JR, MATAIX J: Ageing-related tissue-specific alterations in mitochondrial composition and function are modulated by dietary fat type in the rat. J Bioenerg Biomembr 34: 517-524, 2002.

RAMSEY JJ, HARPER ME, WEINDRUCH R: Restriction of energy intake, energy expenditure, and aging. Free Radic Biol Med 29: 946-968, 2000.

RAMSEY JJ, HAGOPIAN K, KENNY TM, KOOMSON EK, BEVILACQUA L, WEINDRUCH R, HARPER ME: Proton leak and hydrogen peroxide production in liver mitochondria from energy-restricted rats. Am J Physiol 286: E31-E40, 2004.

RAMSEY JJ, HARPER ME, HUMBLE SJ, KOOMSON EK, RAM JJ, BEVILACQUA L, HAGOPIAN K: Influence of mitochondrial membrane fatty acid composition on proton leak and $\mathrm{H}_{2} \mathrm{O}_{2}$ production in liver. Comp Biochem Physiol B Biochem Mol Biol 140: 99-108, 2005.

REEVES PG, NIELSEN FH, FAHEY GC Jr: AIN-93 purified diets for laboratory rodents: final report of the American Institute of Nutrition ad hoc writing committee on the reformulation of the AIN-76A rodent diet. $J$ Nutr 123: 1939-1951, 1993.

SANZ A, CARO P, IBANEZ J, GOMEZ J, GREDILLA R, BARJA G: Dietary restriction at old age lowers mitochondrial oxygen radical production and leak at complex I and oxidative DNA damage in rat brain. J Bioenerg Biomembr 37: 83-90, 2005.

SASTRE J, PALLARDO FV, VINA J: The role of mitochondrial oxidative stress in aging. Free Radic Biol Med 35: 1$8,2003$.

SEIFERT EL, ESTEY C, XUAN JY, HARPER ME: Electron transport chain-dependent and -independent mechanisms of mitochondrial $\mathrm{H}_{2} \mathrm{O}_{2}$ emission during long-chain fatty acid oxidation. J Biol Chem 285: 5748-5758, 2010.

SOHAL RS, WEINDRUCH R: Oxidative stress, caloric restriction, and aging. Science 273: 59-63, 1996.

SOHAL RS, AGARWAL S, CANDAS M, FORSTER MJ, LAL H: Effect of age and caloric restriction on DNA oxidative damage in different tissues of C57BL/6 mice. Mech Ageing Dev 76: 215-224, 1994. 
TAHIN QS, BLUM M, CARAFOLI E: The fatty acid composition of subcellular membranes of rat liver, heart, and brain: diet-induced modifications. Eur J Biochem 121: 5-13, 1981.

VENDITTI P, PAMPLONA R, PORTERO-OTIN M, DE ROSA R, DI MEO S: Effect of experimental and cold exposure induced hyperthyroidism on $\mathrm{H}_{2} \mathrm{O}_{2}$ production and susceptibility to oxidative stress of rat liver mitochondria. Arch Biochem Biophys 447: 11-22, 2006.

VENKATRAMAN J, FERNANDES G: Modulation of age-related alterations in membrane composition and receptorassociated immune functions by food restriction in Fischer 344 rats. Mech Ageing Dev 63: 27-44, 1992.

WALSH ME, SHI Y, VAN REMMEN H: The effects of dietary restriction on oxidative stress in rodents. Free Radic Biol Med 66: 88-99, 2014.

WEINDRUCH R, SOHAL RS: Seminars in medicine of the Beth Israel Deaconess Medical Center. Caloric intake and aging. $N$ Engl J Med 337: 986-994, 1997.

YAMAOKA S, URADE R, KITO M: Mitochondrial function in rats is affected by modification of membrane phospholipids with dietary sardine oil. J Nutr 118: 290-296, 1988.

YU BP: Membrane alteration as a basis of aging and the protective effects of calorie restriction. Mech Ageing Dev 126: 1003-1010, 2005.

YU BP, LIM BO, SUGANO M: Dietary restriction downregulates free radical and lipid peroxide production: plausible mechanism for elongation of life span. J Nutr Sci Vitaminol (Tokyo) 48: 257-264, 2002. 